\title{
An electrophysiological assessment of subclinical lead toxicity in children
}

\author{
Hassan $\mathrm{MS}^{1}$, Sonia $\mathrm{SF}^{2}$, Ara F ${ }^{3}$, Yusuf $\mathrm{MA}^{4}$, Sharif $\mathrm{AR}^{5}$, Rahman $\mathrm{MA}^{6}$, Huque $\mathrm{A}^{7}$
}

\begin{abstract}
Background: While heavy exposure to inorganic lead is capable of inducing symptomatic neuropathy, subclinical neuropathy due to low level of lead exposure remains to be proved. Objectives: This study was assessed peripheral nerve function in environmental lead exposed primary school children. Methods: Electrophysiological evaluation of peripheral nerve function was done in 17 subclinical lead exposed and 17 non-exposed primary school children in an urban industrial area of Dhaka. Lead exposed children had mean blood lead level (BLL) $20.2( \pm 5.17) \mu \mathrm{gm} / \mathrm{dl}$. Non-exposed children had BLL $6.2( \pm 2.82) \mu \mathrm{gm} / \mathrm{dl}$. Results: Electrophysiological evaluation of peripheral nerve function was normal in lead exposed children. Statistical analysis also did not show any significant difference in parameters of nerve function between lead exposed and non-exposed children ( $p$ value $>0.05$ ). Conclusion: This study did not find any electrophysiological evidence of peripheral nerve dysfunction in the environmental lead exposed children compared to nonexposed. [J Shaheed Suhrawardy Med Coll, 2014;6(1): 23-26]
\end{abstract}

Keywords: subclinical lead toxicity, electrophysiological assessment, children

Received: March 2014; Revised: April 2014; Accepted: May 2014

\section{Introduction}

Diagnosis of lead exposure is based on blood lead level measured in micrograms of lead per deciliter of blood ( $\mu \mathrm{gm}$ /dl). World Health Organization (WHO) states that a blood lead level (BLL) of $10 \mu \mathrm{gm} / \mathrm{dl}$ or above is abnormal ${ }^{1}$. BLL $<10 \mu \mathrm{gm} / \mathrm{dl}$ is considered as normal.

Lead is toxic to many organs and tissues including nervous systems ${ }^{2}$. Lead is much more harmful to children than adults because it can affect children's developing nerves and brains ${ }^{3}$. Peripheral nervous system effects are more prominent in adults and central nervous system effects are more prominent in children ${ }^{4}$. While heavy exposure to inorganic lead is capable of inducing symptomatic neuropathy, subclinical neuropathy is more common ${ }^{5-8}$. No unanimity has, however been reached, on the lowest exposures at which such effects are found. Traditionally lead poisoning is described as a purely motor disorder'.

Dhaka, Bangladesh, was discovered to have one of the highest air lead level in the world. It was about $453 \mathrm{ngm} / \mathrm{m} 3$ in 200010 In one study in 2001, almost $90 \%$ of the sampled children had BLL ? 10 ?g/dl in Dhaka ${ }^{11}$. This study assessed peripheral nerve function in environmental lead exposed primary school children of an urban industrial area of Dhaka.

\section{Methodology}

This cross sectional study was carried out in the Department of Neurology at Bangabandhu Sheikh Mujib Medical University, Dhaka from January 2009 to December 2010 for

1. Dr. Mohammad Sayeed Hassan, Junior Consultant, Department of Clinical Neurology, National Institute of Neurosciences \& Hospital, Dhaka

2. Dr. Sheikh Farjana Sonia, MD (Pediatrics) Student, Bangladesh Institute of Child Health, Dhaka

3. Dr. Ferdous Ara, Assistant Professor, Department of Blood Transfusion, National Institute of Neurosciences \& Hospital, Dhaka

4. Dr. Md. Abdullah Yusuf, Assistant Professor, Department of Microbiology, National Institute of Neurosciences \& Hospital, Dhaka

5. Dr. Ahmad Raihan Sharif, Medical Officer, Department of Virology, Institute of Epidemiology, Disease Control Hospital and Research, Dhaka

6. Dr. Md. Atiqur Rahman, Registrar, Department of Cardiology, Sir Salimuallah Medical College, Dhaka

7. Prof. Dr. Anisul Huque, Professor, Department of Neurology, Bangabandhu Sheikh Mujib Medical University, Dhaka

\section{Correspondence}

Dr. Mohammad Sayeed Hassan, Junior Consultant, Department of Clinical Neurology, National Institute of Neurosciences \& Hospital, Sher-E-Bangla Nagar, Agargaon, Dhaka-1207, Bangladesh; Email: dr.sayeed@yahoo.com; Cell no.: +8801711442626

Conflict of interest: None

Financial Support: None

Contributions by authors: MSH and AH contributed to the protocol writing, data analysis as well as data collection. MSH, SFS, MAY and MAR were involved in the manuscript writing as well as review of the manuscript. ARS had performed the statistical analysis of this manuscript. 
a period of two(02) years. Study population was selected from children of 6 to 12 years age of a primary school, where the tannery industries of Dhaka are located. Electrophysiological evaluation of peripheral nerve function was done in 17 lead exposed asymptomatic children with mean blood lead level (BLL) $20.2( \pm 5.17)$ $\mu \mathrm{gm} / \mathrm{dL} .17$ non-exposed children with BLL $6.2( \pm 2.82)$ $\mu \mathrm{gm} / \mathrm{dl}$ were taken as control. Patients suffering from diabetes mellitus or hypothyroidism, children with family history of peripheral neuropathy were excluded from the study. Children with symptoms and signs suggestive of peripheral neuropathy were also excluded. BLL was measured by using a portable lead care instrument (ESA Inc., Chelmsford, MA, USA) from venous blood (0.5 ml). The instrument has been approved by the US Food and Drug Administration (FDA), and is being used in many health centers in the United States. Nerve conduction studies (NCS) were performed by a single neurophysiologist by NIHON KOHDON (Neuropack E) machine. Sensory nerve action potentials were recorded using an antidromic stimulus. The amplitudes were measured from the base line to the peak. Surface electrodes were used for recording and for stimulation. NCS was done in cross limb (right upper and left lower limb). All data was recorded systematically in preformed data collection form and quantitative data was expressed as mean and standard deviation. Statistical analyses of the results were obtained by using window based computer software devised with Statistical Packages for Social Sciences (SPSS-16). Statistical tests for significance of difference of means were done using unpaired $t$ test.

\section{Results}

There were no statistical significant difference between the exposed and non-exposed groups in respect of age, sex and socioeconomic status. All parameters of motor nerve functions e.g. motor conduction velocity $(\mathrm{MCV})$, distal motor latencies (DML) and motor amplitude (MA) measured were within normal level in both exposed and nonexposed groups. Statistical analysis (unpaired $t$ test) did not find any significant difference in motor NCS between the children with normal and elevated BLL.

All parameters of sensory nerve functions e.g. distal sensory latencies (DSL), sensory amplitudes (SNAP) and sensory conduction velocity (NCV) were within normal limit in both exposed and non-exposed groups. Statistical analysis (unpaired $t$ test) did not find any significant difference in sensory NCS between the children with normal and elevated BLL (table 2).

\section{Discussion}

Most previous studies of exposed workers with raised lead concentrations have not noted clinical neuropathic abnormalities; despite mild electrophysiological abnormalities ${ }^{5-8,12-15}$. Traditionally the neuromuscular disorder associated with lead poisoning has been purely motor but some studies showed mild sensory and autonomic abnormalities ${ }^{16-17}$. After a critical review and meta-analysis on NCS in 32 studies on asymptomatic lead workers, Davis and Svendsgaard ${ }^{18}$ concluded that there were no substantive differences in NCS between the asymptomatic workers and normal controls. This result is consistent with present study findings as no substantive differences were found in NCS between the asymptomatic rise of BLL and normal controls.

Table 1: Comparison of means $( \pm$ SD) of motor nerve functions between exposed and non-exposed children

\begin{tabular}{|c|c|c|c|c|c|c|c|c|}
\hline \multirow[b]{2}{*}{ 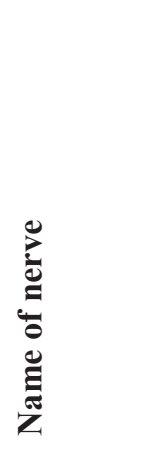 } & \multicolumn{3}{|c|}{$\begin{array}{l}\text { Distal motor } \\
\text { latency (ms) }\end{array}$} & \multicolumn{3}{|c|}{$\begin{array}{c}\text { Motor } \\
\text { amplitude (mv) }\end{array}$} & \multicolumn{2}{|c|}{$\begin{array}{l}\text { Motor conduction } \\
\text { velocity }(\mathrm{m} / \mathrm{s})\end{array}$} \\
\hline & 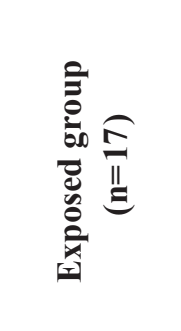 & 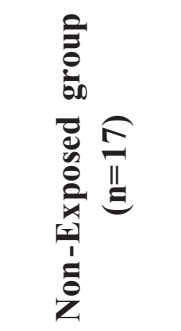 & 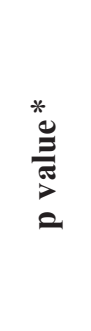 & 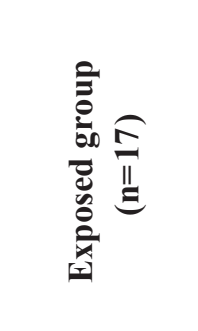 & 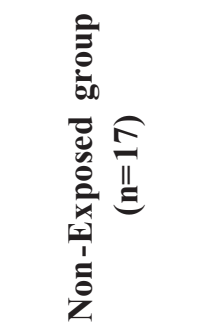 & 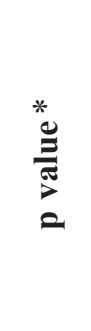 & 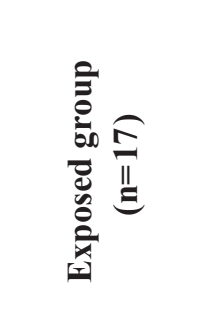 & 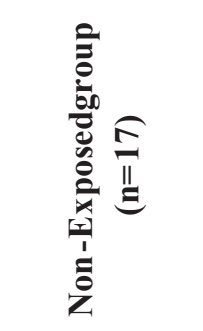 \\
\hline Median & $2.73 \pm 0.24$ & $2.62 \pm 0.41$ & 0.24 & $13.41 \pm 4.02$ & $13.76 \pm 4.50$ & 0.42 & $59.23 \pm 6.53$ & $60.93 \pm 5.75$ \\
\hline Ulnar & $1.81 \pm 0.29$ & $1.76 \pm 0.38$ & 0.23 & $7.40 \pm 1.37$ & $8.25 \pm 1.86$ & 0.32 & $61.56 \pm 5.53$ & $60.08 \pm 7.79$ \\
\hline Tibial & $3.06 \pm 0.22$ & $2.80 \pm 0.29$ & 0.30 & $19.37 \pm 4.93$ & $17.87 \pm 4.66$ & 0.82 & $51.91 \pm 4.04$ & $49.76 \pm 4.08$ \\
\hline Peroneal & $3.70 \pm 0.73$ & $3.59 \pm 0.76$ & 0.56 & $4.61 \pm 1.78$ & $4.81 \pm 1.69$ & 0.68 & $58.01 \pm 9.05$ & $56.98 \pm 7.67$ \\
\hline
\end{tabular}

$*_{t}$ test was done to measure the level of significance; Data was expressed as Mean $\pm \mathrm{SD}$; NS $=$ not significant, $\mathrm{ms}=$ mili second, $\mathrm{mv}=$ mili volt, $\mathrm{m} / \mathrm{s}=$ meter/ second. 
Table 2- Comparison of means $( \pm \mathrm{SD})$ of sensory nerve functions between the exposed and non-exposed children.

\begin{tabular}{|c|c|c|c|c|c|c|c|c|c|}
\hline \multirow{2}{*}{ 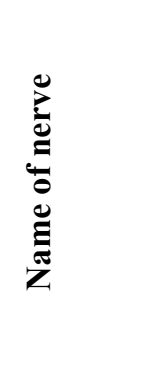 } & \multicolumn{2}{|c|}{$\begin{array}{c}\text { Sensory } \\
\text { latency (ms) }\end{array}$} & \multicolumn{4}{|c|}{$\begin{array}{c}\text { Sensory } \\
\text { amplitude ( } \mu \mathrm{v})\end{array}$} & \multicolumn{3}{|c|}{$\begin{array}{l}\text { Sensory conduction } \\
\text { velocity }(\mathbf{m} / \mathbf{s})\end{array}$} \\
\hline & 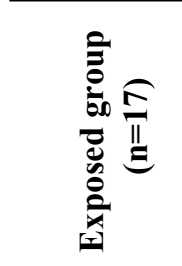 & 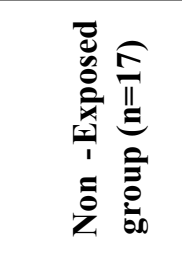 & 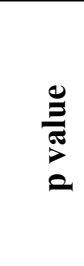 & 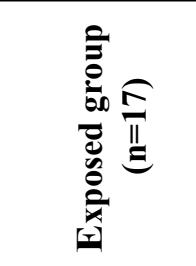 & 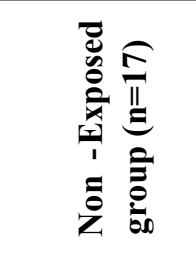 & 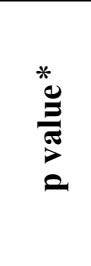 & 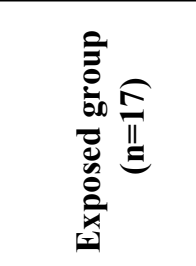 & 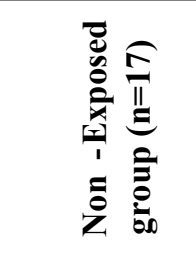 & $\begin{array}{l}\stackrel{0}{E} \\
\frac{\pi}{\pi} \\
\text { en }\end{array}$ \\
\hline Median & $1.90 \pm 0.21$ & $1.82 \pm 0.22$ & 0.58 & $32.62 \pm 7.63$ & $33.29 \pm 8.35$ & 0.80 & $57.04 \pm 8.89$ & $58.83 \pm 7.26$ & 0.51 \\
\hline Ulnar & $1.78 \pm 0.23$ & $1.70 \pm 0.21$ & 0.65 & $30.57 \pm 7.46$ & $31.26 \pm 7.82$ & 0.43 & $57.77 \pm 2.53$ & $59.70 \pm 5.96$ & 0.52 \\
\hline Sural & $1.86 \pm 0.16$ & $1.79 \pm 0.21$ & 0.19 & $34.03 \pm 6.48$ & $35.63 \pm 8.59$ & 0.48 & $54.70 \pm 3.60$ & $55.23 \pm 3.99$ & 0.68 \\
\hline
\end{tabular}

$*_{t}$ test was done to measure the level of significance; Data was expressed as Mean $\pm \mathrm{SD} ; \mathrm{NS}=$ not significant, $\mathrm{ms}=$ mili second, $\mu \mathrm{v}=$ micro volt, $\mathrm{m} / \mathrm{s}=\mathrm{meter} / \mathrm{second}$

Yeh et al reported that early conduction abnormalities in lead neuropathy are manifested by prolonged distal latencies rather than a slowing of NCV. Jeyaratnam et a $1^{19}$ proposed that the distal segment of the peripheral nerves should show the earliest change and also suggested that the distal latency is a sensitive indicator of lead neuropathy. In this study no abnormalities were found in distal latency.

Schwartz et al ${ }^{14}$ performed clinical and electrophysiological evaluation in 202 five to nine year-old children living near a lead smelter in Idaho. Blood lead levels ranged from 13 to $97 \mu \mathrm{gm} / \mathrm{dl}$. There was no clinical feature of neuropathy in those children. However, asymptomatic increase of BLL was associated with slowing of nerve conduction velocity in motor nerves. In this study, the age group was nearly similar (6 to 12 year). BLL was much lower (3.6-31.9 $\mu \mathrm{gm}$ /dl) in the study comparison to previous study. No difference was found in electrophysiological evaluation; which is contrary to previous study finding. One explanation to this finding is that, BLL of this current study subjects were significantly low. Symptomatic neuropathy usually develops after long exposure of high blood lead level, but the exact time duration and blood lead level causing peripheral neuropathy is not yet established. Most of the previous studies done in subjects with asymptomatic increase of blood lead level did not find any electrophysiological abnormalities comparing to normal subjects $^{19}$. The findings of this study are similar to their findings in this sense.

\section{Conclusion}

Overt lead poisoning is now uncommon in developed countries due to an improvement in occupational hygiene and medical surveillance. But in a developing country like Bangladesh, lead poisoning seems to be a matter of concern both in occupational and environmental aspects. This study did not find any electrophysiological evidence of peripheral nerve dysfunction in the environmental lead exposed children compared to non-exposed. There is a plan to reevaluate this cohort in the future periodically.

\section{References}

1. Rossi E. Low level environmental lead exposure-a continuing challenge. The Clinical biochemist 2008; 29 (2): 63-70.

2. Windebank AJ, Dyck PJ, Thomas PK, Griyn JW. Peripheral neuropathy. WB Sanders, 3rd ed. Philadelphia. 1993:1549-70.

3. Cleveland LM, Minter ML, Cobb KA, Scott AA, German VF. Lead hazards for pregnant women and children: American Journal of Nursing 2008; 108(10):40-9.

4. Hu H, Shih R, Rothenberg S, Schwartz S. The epidemiology of lead toxicity in adults: measuring dose and consideration of other methodological issues. Environmental Health Perspectives 2007; 115 (3):455-62

5. Seppäläinen AM, Hernberg S. Sensitive technique for detecting subclinical lead neuropathy. British journal of industrial medicine, 1972;29(4): 443-449

6. Seppalainen AM, Tola S, Hernberg S, Kock B. Subclinical neuropathy at "safe" levels of lead exposure. Arch Environ Health 1975;30: 180-3

7. Nielsen CJ, Nielsen VK, Kirkby H, Gyntelberg F. Absence of peripheral neuropathy in long-term lead-exposed subjects. Acta Neurol Scand 1982;65:241 -7

8. Triebig G, Weltle D, Valentin H. Investigations on neurotoxicity of chemical substances at the workplace. V. Determination of the motor and sensory nerve conduction velocity in persons occupationally exposed to lead. Int Arch Occup Environ Health 1984;53:189-204.

9. Windebank AJ. Metal neuropathy. In: Dyck PJ, Thomas PK, GriYn JW, Peripheral neuropathy. 3rd ed. Philadelphia: WB Sanders, 1993:1549-70.

10. Lovei M. Eliminating a silent threat: World Bank support for the global phase out of lead from gasoline. In: Proceedings of International Conference on Lead Poisoning, Bangalore, India, 8-10 February 1999. Bangalore, The George Foundation, 1999:169-80.

11. Khaliquzzman M. Trace element composition of size fractionated airborne particulate matter in urban and rural areas in Bangladesh report. Dhaka, Accelerator Facilities Division and Chemistry Division, Atomic Energy Centre, 1997.

12. Catton MJ, Harrison MJG, Fullerton PM, Subclinical neuropathy in lead workers. BMJ 1970; ii: 80-2.

13. Araki S, Honma T, Yanagihara S. Recovery of slowed nerve conduction velocity in lead-exposed workers. Int Arch Occupational Environmental Health 1980; 46:151-7.

14. Schwartz J, Landrigan PJ, Feldman RG, Silbergeld EK, Baker ELJr., von Lindern IH. Threshold effect in lead-induced peripheral neuropathy. 
The Journal of Pediatrics 1998;112(1):12-17

15. Rubens O, Logina I, Kravale I, et al. Peripheral neuropathy in chronic occupational inorganic lead exposure: a clinical and electrophysiological study. Journal of Neurology, Neurosurgery \& Psychiatry 2001;71:200-204

16. Shinj OH. Clinical Electromyography and Nerve Conduction Studies; Third Edition 2003; Section 7; Page 86-106.

17. Davis JM, Svendsgaard DJ. Nerve conduction velocity and lead: a critical review and meta-analysis. In: Advances in neurobehavior toxicology: applications in environmental and occupational health. Chelsea, MI: Lewis, 1990: 353-76.

18. Yeh J-H, Chang Y-C, Wang J-D. Combined electroneurographic and electromyographic studies in lead workers. Occupational and environmental medicine, 1995;52(6):415-419

19. Jeyaratnam J, Devathasan G, Ong CN, et al.: Neurophysiological studies on workers exposed to lead. British journal of industrial medicine 1985;42:173-177 